\title{
Essay
}

\section{Nothing in Evolution Makes Sense Except in the Light of DNA}

\author{
Steven T. Kalinowski, ${ }^{*}$ Mary J. Leonard, ${ }^{\dagger}$ and Tessa M. Andrews* \\ Departments of *Ecology and ${ }^{\dagger}$ Education, Montana State University, Bozeman, MT 59717
}

Submitted December 1, 2009; Revised April 8, 2010; Accepted April 9, 2010

Monitoring Editor: Gary Reiness

\begin{abstract}
Natural selection is one of the most important concepts for biology students to understand, but students frequently have misconceptions regarding how natural selection operates. Many of these misconceptions, such as a belief in "Lamarckian" evolution, are based on a misunderstanding of inheritance. In this essay, we argue that evolution instructors should clarify the genetic basis of natural selection by discussing examples of DNA sequences that affect fitness. Such examples are useful for showing how natural selection works, for establishing connections between genetics and evolution, and for creating cognitive conflict within students having misconceptions. We describe several examples of genes that instructors might use during lectures, and present preliminary evidence from our classroom that an evolution curriculum rich in DNA sequences is effective at reducing student misconceptions of natural selection.
\end{abstract}

\section{INTRODUCTION}

"Darwin would have loved DNA."

Bromham (2009)

Introductory textbooks for biology majors (e.g., Campbell et al., 2008) typically contain 1000 pages, 2000 terms, and hundreds of concepts. Obviously, no student can learn all of this during a conventional two-semester sequence of introductory biology. Therefore, one of the most important roles of an instructor is to determine which concepts in the book students need to learn. Every instructor will select and emphasize different topics, but some concepts are so useful that almost every instructor will include them. Three such topics include: the relationship between organism form and function, the role of DNA in inheritance, and the theory of evolution. The inclusion of evolutionary theory in such a list is incontrovertible. Dobzhansky (1973) famously argued that "nothing in biology makes sense except in the light of evolution" and best-selling textbook author Neil Campbell (Campbell et al., 2008, p. 3) described evolution as the "overarching theme of biology."

DOI: $10.1187 /$ cbe.09-12-0088

Address correspondence to: Steven T. Kalinowski (skalinowski@ montana.edu).
Despite the central importance of evolution to biology, college students frequently do not understand evolutionespecially the cause of most evolutionary change, natural selection (Brumby, 1984; Sundberg and Dini, 1993; Alters and Nelson, 2002; Nehm and Reilly, 2007). In our experience, many college instructors are quick to blame religion, but several studies have shown this is not the case (Bishop and Anderson, 1990; Demastes et al., 1995; Ingram and Nelson, 2006). Natural selection is an inherently difficult process for students to grasp. "It is almost if", as Dawkins (1986, p. xi) wrote, "the human brain were specifically designed to misunderstand Darwinism." Natural selection may be a simple concept-even a "staggeringly" simple one (Coyne, 2009, p. xvi) - but this does not mean it is easy to grasp. Newton's laws of motion are also simple but are notoriously difficult for undergraduate students to comprehend (e.g., Hake, 1998) because many students have everyday notions about physics that are not correct.

Three decades of research clearly shows many students have fundamental misconceptions regarding how natural selection works (for review, see Gregory, 2009). Surveys have documented a diverse array of misconceptions (e.g., Nehm and Schonfeld, 2008; see table 2), but the most common are variations of the belief that individuals evolve. Students believe that individual organisms change, and then pass on traits acquired during their lifetime to their offspring. Students frequently cite three agents of such change: the use or disuse of body parts, the needs or desires of 
individuals (or the species), and the direct effect of the environment (Brumby, 1984; Bishop and Anderson, 1990; Bardapurkar, 2008; Nehm and Schonfeld, 2008). For example, many students, like Lamarck (1809, p. 122), believe that giraffes have long necks because previous generations of giraffes strained their necks to feed in tall trees, and passed lengthened necks to their offspring. Mayr (1982) called such genetic changes "soft" inheritance, which he contrasted with "hard" inheritance-the idea that genes are passed unchanged from one generation to the next.

Student difficulty in understanding the genetic basis of natural selection is understandable; soft inheritance is consistent with everyday experiences with growth and reproduction. Students see that people's bodies are affected by use and disuse, and see that children tend to be similar to their parents. Together, these observations suggest that traits acquired during the lifetime of an individual can be inherited. The history of genetics (for a book-length review, see Mayr, 1982) shows many evolutionary biologists struggled with these ideas and that even Darwin was not immune to them. In fact, chapter 5 of On the Origin of Species contains the surprising statement, "There can be little doubt that use in our domestic animals strengthens and enlarges certain parts and disuse diminishes them; and that such modifications are inherited." Uncertainty regarding the nature of inheritance and mutations continued from the publication of On the Origin of Species in 1859 almost up to the discovery of the structure of DNA in 1953, and this controversy postponed acceptance of natural selection as the principal cause of natural selection for $80 \mathrm{yr}$ (Mayr, 1982).

Perhaps because they are plausible, student misconceptions regarding natural selection (and other natural phenomena) are very resistant to instruction (for reviews, see Tanner and Allen, 2005; Sinatra et al., 2008, Gregory, 2009). Simply telling students the correct explanation for a phenomenon is unlikely to be effective, and even the best traditional instruction is unlikely to have an impact on students' misconceptions (Hake, 1998). This is because students do not learn by passively accumulating knowledge presented to them. Students learn by integrating new knowledge with their existing knowledge (Piaget, 1978; Bransford et al., 2000), and if their existing knowledge is not compatible with scientific information, misconceptions can interfere with students' ability to understand new information.

To have a fighting chance of correcting student misconceptions, instructors must specifically design instruction to address misconceptions. However, even such instruction is likely to be only partially effective. For example, Bishop and Anderson (1990) documented that half of the students in an Introductory Biology course left the course with misconceptions regarding natural selection-even though lectures and laboratory exercises were specifically designed to refute misconceptions (Bishop and Anderson, 1990). Nehm and Reilly (2007) found that $70 \%$ of biology majors had at least one misconception regarding natural selection-even though the instructors emphasized evolution as a theme running throughout the course, and relied extensively on activelearning exercises to promote a deep understanding.

Darwin developed the theory of natural selection despite having substantial misconceptions regarding inheritance, and Dobzhansky (1937) managed to explain the genetic basis of evolution without knowing what DNA was, but these insights required extraordinary perception and years of effort (Mayr and Provine, 1980). It would be unfair to expect such insight from undergraduate students, but, to some extent, this is what introductory biology textbooks ask of students. As we will review below, introductory biology textbooks do not illustrate how natural selection works at the molecular level; genes are treated as abstract units of inheritance. We believe that the absence of DNA from evolution instruction helps perpetuate student misconceptions regarding evolution, and the thesis of this paper is that students would understand evolution better if instructors made the genetic basis of evolution explicit at the DNA sequence level-ideally as part of a curriculum specifically designed to correct student misconceptions. In this essay, we discuss how and why DNA sequences should be used to illuminate natural selection, contrast this with how textbooks typically cover evolutionary genetics, and provide examples of gene sequences and classroom activities that instructors can use. We devote most of our discussion to natural selection but we also discuss speciation and macroevolution toward the end of this essay.

\section{TEACHING FOR CONCEPTUAL CHANGE}

Students are more likely to replace misconceptions with a scientifically supported view of the world when educators use instructional techniques specifically designed for this goal. The instructional techniques that are useful for correcting student misconceptions regarding natural selection are useful for correcting misconceptions in any subject. Therefore, we first discuss general classroom practices that can be used for teaching for conceptual change, and then we discuss how these practices can be applied to teach natural selection to introductory biology students.

Identifying the most effective instructional practices for correcting student misconceptions is an active field of research (Vosniadou, 2008), and there are several different instructional approaches for helping students to change misconceptions. However, all approaches agree that instructors must take students' prior knowledge into account and help students integrate new knowledge with their existing knowledge (di Sessa, 2006; National Research Council [NRC] 2005, see chapter 1; Tanner and Allen, 2005). Three specific instructional strategies (described below) have been identified as useful for what is often called "teaching for conceptual change."

\section{Elicit Students' Ideas throughout Instruction}

Teaching for conceptual change requires working directly with students' ideas. Instructors, therefore, should first elicit students' pre-existing ideas when introducing a new topic (Hewson et al., 1998). This helps students recognize and articulate their own conceptions (which is the first step in changing them). While eliciting ideas from students, instructors should provide opportunities for students to hear and read the ideas of their peers. This will frequently reveal a diversity of contrasting ideas, which will "suggest the need to choose between them" (Hewson et al., 1998, p. 203). Also, instructors should monitor what students say and write throughout instruction. Because misconceptions are resis- 
tant to change (Posner et al., 1982), formative assessment (ongoing, often informal, assessment for the purpose of improving teaching and learning; see Bransford et al., 2000) is useful for determining whether instruction is successful.

\section{Create Situations That Challenge Students' Misconceptions}

One strategy for correcting misconceptions is to challenge them directly by "creating cognitive conflict," presenting students with new ideas that conflict with their pre-existing ideas about a phenomenon (Scott et al., 1991). Strategies for creating cognitive conflict include presenting phenomena that cannot be adequately explained by their misconceptions, having students conduct experiments to test hypotheses, asking students to develop multiple explanations for phenomena and then evaluate pros and cons of each, and asking questions that reveal weaknesses in students' ideas (Nussbaum and Novick, 1982; Vosniadou and Brewer, 1987; Guzetti et al., 1993; Hewson et al., 1998).

\section{Emphasize Conceptual Frameworks Rather Than Rote Memorization of Facts}

Students are more likely to note inconsistencies between their misconceptions and new information if they go beyond rote memorization and engage in meaningful learning, whereby they attempt to make connections between new and old information (Bransford et al., 2000). Instructors can help students organize knowledge in a conceptual framework by explicitly pointing out such connections. Conceptual frameworks integrate knowledge of facts and of concepts, and require deep understanding of concepts. This means instructors should teach key concepts in depth and have students study multiple examples of a concept that are rich with factual information (Catrambone and Holyoak, 1989; Bransford et al., 2000; Mestre, 2003).

\section{TEACHING NATURAL SELECTION FOR CONCEPTUAL CHANGE}

The general approach for teaching for conceptual change outlined in the preceding section is useful for addressing student misconceptions regarding natural selection; however, instructors should be forewarned that teaching for conceptual change in an evolution classroom may not be as easy as for other courses. A physics instructor might use a classroom demonstration to convince students that heavy objects do not fall faster than less heavy objects, but evolution instructors do not have this luxury. Natural selection is too slow to observe in the classroom, and DNA is invisible to the naked eye. Because of this, convincing students that evolution does not proceed via the inheritance of acquired traits requires getting students to reassess their beliefs.

Of the three teaching for conceptual change instructional strategies described above, the easiest to implement is eliciting student ideas. Open-ended questions are excellent for getting students to express misconceptions, and an appropriate question is almost guaranteed to bring forth a wide range of misconceptions. For example, if asked how cheetahs evolved to run fast, many students will report that cheetahs became faster because they needed to catch prey
(Bishop and Anderson, 1990). The challenge for teaching natural selection is to help students understand that evolution does not work this way.

Cognitive conflict can be effective for changing how students understand the natural world; the challenge is how to create it. One possible approach for teaching natural selection would be to show students experimental data that refutes soft inheritance. The difficulty with this strategy is that finding a definitive experiment is difficult; decades of experiments in the late nineteenth and early twentieth centuries were unable to unequivocally determine whether acquired traits could be inherited (Mayr, 1982; for a review of what was known about the inheritance of acquired traits in the early twentieth century, see Morgan, 1932). Nonetheless, two historic experiments may be useful for countering student misconceptions concerning the role of disuse in evolution. Payne (1910) raised 49 generations of fruit flies in the dark and found no evidence that their eyes weakened during this time, and Weisman (1889) cut the tails off of five generations of mice and observed no changes in the tails of their offspring. These experiments both tested the effect of disuse of body parts upon subsequent generations. Many students believe that animals evolve body structures because they use them frequently, and the experiments of Payne and Weisman do not test this hypothesis. Despite this shortcoming, Jensen and Finley (1996) showed that a historically rich curriculum that discussed Lamarckian evolution and these specific two experiments increased understanding of natural selection and decreased misconceptions compared with a less historically rich curriculum.

Because there are no definitive experiments that refute soft inheritance, the most effective approach for dealing with student misconceptions regarding natural selection may be to help students make connections between evolution and genetics - two of the most important concepts in biology. If students build a conceptual framework that connects genetics and natural selection, they should realize that soft inheritance is inconsistent with their understanding of DNA's role in inheritance. This is the central strategy for teaching natural selection that we advocate in this essay. Showing students the DNA sequence of adaptive (or maladaptive) traits should help students realize that use or disuse of a body part will not change the nucleotide sequence of a gene, and that mutations caused by UV radiation or errors in DNA replication are unlikely to cause the specific genetic change that would benefit an individual.

Examples are essential for students to understand concepts (NRC, 2005), so instructors should routinely show students nucleotide sequences that affect traits being discussed. Exposing students to multiple examples of a concept promotes better understanding, and enhances students' abilities to apply the concept to new scenarios (e.g., Mestre, 2003). In addition, study of multiple examples increases the chance of students identifying and overcoming persistent misconceptions (McDermott, 1998).

\section{TEXTBOOK COVERAGE OF NATURAL SELECTION}

"It is probable ... that writers of books on evolution ten or twenty years hence will ... begin by describing 
the nature of the physical basis of inheritance, its modes of change by mutation..., its remarkable uniformity in all cellular organisms, and its important variations in detail. They will then point out how the nature of this mechanism governs or limits the evolutionary process ..."

Huxley (1943), p. 126

Up to this point, we have argued that students learning natural selection need to see the DNA sequence of the genes that affect fitness in order to recognize that individuals do not evolve. To support this claim, we argued that student misconceptions regarding natural selection are frequently based on a misunderstanding of genetics and that correcting these misconceptions requires making conceptual connections between genetics and evolution. We have argued that discussing examples of genes under selection is an effective way to accomplish this. Next, we will examine whether introductory biology textbooks do this.

Given the importance of understanding inheritance for understanding evolution, we might expect, as Huxley did in 1943, that textbooks would emphasize the physical basis of inheritance and would "point out how the nature of this mechanism governs or limits the evolutionary process." To determine whether textbooks do this or not, we examined three widely used college textbooks: Biology by Campbell et al. (2008), Biological Science by Freeman (2008), and Life by Sadava et al. (2008). For each textbook, we noted how genetic variation at the DNA sequence level was related to natural selection.

The three books that we examined had similar treatments of evolution-at least for our purposes-so we restrict our discussion here to Biology, because it is the most widely used biology textbook in the United States. Biology is an introductory biology text for biology majors. It is divided into eight units, one of which is "Mechanisms of Evolution." This unit has four chapters: "A Darwinian view of life," "The evolution of populations," "The origin of species," and "The history of life on earth." Natural selection is covered in the first of these chapters. The chapter clearly articulates that the requirements for evolution by natural selection include the following: 1) There is variation in a population for a trait; 2) Differences among individuals for the trait are heritable; and 3) Individuals with favorable traits are more likely to survive or reproduce. Biology clearly states that traits must be "heritable" for natural selection to work, and this point is repeated five times within two pages (pp. 458 and 459).

The remaining three chapters in the unit on evolutionary mechanisms discuss many genetic topics. For example, the first "key concept" in the next chapter is that mutation and recombination produce genetic variation, which makes evolution possible. Numerous other genetic topics are explored in the evolution unit. These include the following: gene pools, allele frequencies, Hardy-Weinberg equilibrium, genetic bottlenecks, genetic drift, gene flow, relative fitness, good genes theory, heterozygote advantage, frequency-dependent selection, neutral genetic variation, polyploidy, hybrid zones, speciation, self-replicating RNA, and evolutionary aspects of development. The unit covers almost the full breadth of evolutionary biology and has a strong emphasis on genetics. However, the entire evolution unit does not contain a single DNA sequence! The evolution unit was written as if Watson and Crick never discovered the structure of DNA or the human genome was never sequenced. Genes are treated as abstract entities located on chromosomes-just as Dobzhansky struggled to understand them in 1937. This is regrettable, because students are known to have difficulty understanding the genetic basis of evolution. It is also inexplicable; the first chapter of Biology indicates that "heritable information in the form of DNA" is one of the main themes that unifies the book.

\section{DNA SEQUENCES TO INCORPORATE INTO LECTURES}

As shown above, widely used introductory biology textbooks do not use examples of DNA sequences to illustrate the genetic basis of evolution. If textbooks are a reliable indicator of how evolution is taught in the United Statesand we suspect that they are-many students will not see a single example of a gene while studying evolution. This is a pity, because the evolutionary genetics literature is filled with fascinating examples of molecular evolution that could be used to present students with the data that support scientific explanations of natural selection and to make connections between genetics and evolution. The literature is sufficiently rich that there is no reason that instruction cannot provide students with multiple examples of selection at work. Here, we briefly describe six genes that have been under selection.

\section{Coat Color in Oldfield Mice}

Coat color in the oldfield mouse, Peromyscus polionotus, provides a fine example of adaptation at the molecular level. Oldfield mice live in the southeastern United States, and there are eight extant subspecies: a wide-ranging mainland subspecies and seven coastal subspecies that each inhabit a short section of the Gulf or Atlantic Coast. Coat coloration varies considerably among subspecies (Sumner, 1929) and tends to match the color of the soil on which the mice live (Belk and Smith, 1996). The mainland subspecies, P. p. subgriseus, lives on the darkest soils and has the darkest fur. The Santa Rosa Island subspecies, P. p. leucocephalus, lives on brilliant white sand dunes and has the lightest fur (for a PowerPoint slide depicting this variation, see Hoekstra et al., 2006). Owl predation experiments show that mice are less likely to be caught by owls when they are on their native soils (Kaufman, 1974).

The light coloration of the Santa Rosa Island mice can be attributed to a single amino acid change in melanocortin-1 receptor (Mc1r) (Hoekstra et al., 2006), a gene that plays an important role in hair coloration in mammals (Table 1). Virtually all mice on Santa Rosa Island have a light-colored Mc1r allele. A survey of 14 other species of Peromyscus showed that none of the other species have this allele, suggesting that the mutation for light fur occurred on Santa Rosa Island. Instructors could use this example in many ways; we like to ask our students what a field mouse with dark fur living on white sand dunes could do to lighten her coat or the coat of her offspring. The answer: nothing. 
Table 1. Mcr1 DNA sequences for oldfield mice ${ }^{\mathrm{a}}$

\begin{tabular}{|c|c|c|c|c|c|c|c|c|c|}
\hline & 10 & 20 & 30 & 40 & 50 & 60 & 70 & 80 & 90 \\
\hline \multirow{2}{*}{$\begin{array}{l}P . p . \text { subgriseus } \\
P . p . \text { leucocephalus }\end{array}$} & \multicolumn{9}{|c|}{ ATGCCCACCCAGGGGCCTCAGAAGAGGCTTCTGGGTTCTCTCAACTCCACCTCCACAGCCACCCCTCACCTTGGACTGGCCACAAACCAG } \\
\hline & 100 & 110 & 120 & 130 & 140 & 150 & 160 & 170 & 180 \\
\hline \multirow{2}{*}{$\begin{array}{l}\text { P. p. subgriseus } \\
\text { P.p. leucocephalus }\end{array}$} & \multicolumn{9}{|c|}{ ACA GG GCCTTGGTGCCTGCAGGTGTCTGTCCCGGATGGCCTCTTCCTCAGCCTGGGGCTGGTGAGTCTGGTGGAGAATGTCTGGTCGTG } \\
\hline & 190 & 200 & 210 & 220 & 230 & 240 & 250 & 260 & 270 \\
\hline \multirow{2}{*}{$\begin{array}{l}\text { P. p. subgriseus } \\
\text { P.p. leucocephalus }\end{array}$} & \multicolumn{9}{|c|}{ ATAGCCATCACCAAAAACCGCAACCTGCACTCGCCCATGTATTCCTTCATCTGCTGTCTGGCCCTGTCTGACCTGATGGTGAGTATAAGC } \\
\hline & \multicolumn{8}{|c|}{ 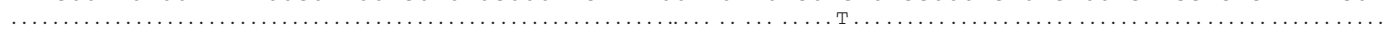 } & 36 \\
\hline \multirow{2}{*}{$\begin{array}{l}\text { P. p. subgriseus } \\
\text { P.p. leucocephalus }\end{array}$} & \multicolumn{9}{|c|}{ TTGGTGCTGGAGACGGCTATCATCCTGCTGCTGGAGGCAGGGGCCCTGGTGACCCGGGCCGCTTTGGTGCAACAGCTGGACAATGTCATT } \\
\hline & \multicolumn{8}{|c|}{ 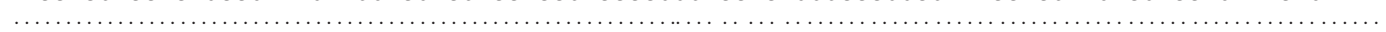 } & $\begin{array}{l}\cdots \\
450\end{array}$ \\
\hline \multirow{2}{*}{$\begin{array}{l}\text { P. p. subgriseus } \\
\text { P. p. leucocephalus }\end{array}$} & \multicolumn{9}{|c|}{ 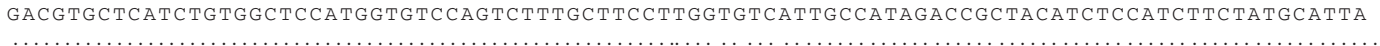 } \\
\hline & $\begin{array}{r}460 \\
40 \cdots \cdots\end{array}$ & $\begin{array}{l}\cdots \\
470\end{array}$ & $\begin{array}{l}\cdots \\
480\end{array}$ & 49 & 500 & ... & $\ldots$ & 530 & $\begin{array}{l}\cdots \\
540\end{array}$ \\
\hline \multirow{2}{*}{$\begin{array}{l}\text { P.p. subgriseus } \\
\text { P.p. leucocephalus }\end{array}$} & \multicolumn{9}{|c|}{ CGTTATCACAGCATTGTGACGCTGCCCCGGGCACGACGGGCCATCGTGGGCATCTGGGTGGCCAGCATCTTCTTCAGCACCCTCTTTATC } \\
\hline & 550 & 360 & 570 & 580 & 590 & 600 & 610 & 620 & 630 \\
\hline \multirow{2}{*}{$\begin{array}{l}\text { P. p. subgriseus } \\
\text { P.p. leucocephalus }\end{array}$} & \multicolumn{9}{|c|}{ ACСTACTACAACCACACAGCCGTCCTAATCTGCCTTGTCACTTTCTTTCTAGCCATGCTGGCCCTCATGGCAATCTGTATGTCCACATG } \\
\hline & \multicolumn{9}{|c|}{ 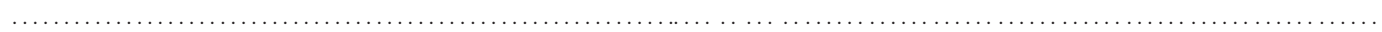 } \\
\hline \multirow{2}{*}{$\begin{array}{l}\text { P.p. subgriseus } \\
\text { P.p. leucocephalus }\end{array}$} & \multicolumn{9}{|c|}{ СTCACCCGAGCATACCAGCATGCTCAGGGGATTGCCCAGCTCCAGAAGAGGCAGGGCTCCACCCGCCAAGGCTTCTGCCTTAAGGGTGCT } \\
\hline & 730 & 740 & 750 & 760 & 770 & 780 & 790 & & 810 \\
\hline \multirow{2}{*}{$\begin{array}{l}\text { P.p. subgriseus } \\
\text { P.p. leucocephalus }\end{array}$} & \multicolumn{9}{|c|}{$\begin{array}{l}\text { GCС } \\
1\end{array}$} \\
\hline & $\begin{array}{r}\cdots \\
820\end{array}$ & … & 340 & .... & 860 & ... & 380 & 890 & ... \\
\hline \multirow{2}{*}{$\begin{array}{l}\text { P.p. subgriseus } \\
\text { P. p. leucocephalus }\end{array}$} & \multicolumn{9}{|c|}{ 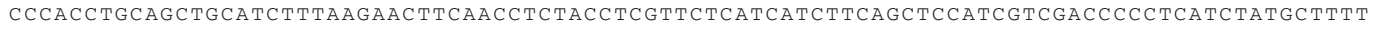 } \\
\hline & \multicolumn{5}{|c|}{ 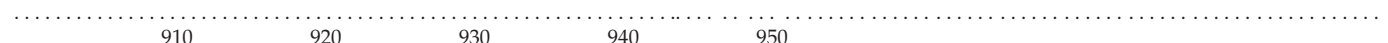 } & & & & \\
\hline P. p. subgriseus & \multirow{2}{*}{\multicolumn{9}{|c|}{ CGGAGCCAGGAGCTCCGCATGACACTCAGGGAGGTGCTGCTGTGCTCCTGGTGA }} \\
\hline P.p. leucocephalus & & & & & & & & & \\
\hline
\end{tabular}

${ }^{a}$ P. p. subgriseus lives on dark soils and has dark fur. P. p. leucocephalus lives on white sand beaches and has light-colored fur. Dots in the DNA sequence indicate nucleotide similarity to the sequence above.

\section{Alcohol Metabolism in Fruit Flies}

The enzyme alcohol dehydrogenase (Adh) facilitates the conversion of ethanol to acetaldehyde and provides another example of how selection operates at the DNA sequence level. There are two common Adh alleles in populations of the common fruit fly Drosophila melanogaster: Adh-S and Adh-F. Adh-F is more efficient at metabolizing ethanol, but $A d h-S$ is more effective at warm temperatures. When laboratory populations are selected for ethanol tolerance, Adh- $F$ increases in frequency (e.g., Cavener and Clegg, 1975). When laboratory populations are raised at warm temperatures, Adh-S increases in frequency (e.g., Van Delden, 1984). In nature, most populations have both alleles, and as global temperatures have warmed, the $A d h-S$ allele has increased in frequency (Umina et al., 2005). One nice feature of the Adh example is that it illustrates that adaptations often have trade-offs (i.e., heat tolerance is gained at the expense of rate of ethanol conversion).

\section{Warfarin Resistance in Rats}

Warfarin is an anticoagulant used in humans to prevent blood clots and thereby to avoid strokes. Warfarin is also a pesticide used to kill rats, and the history of this application provides a third example of natural selection at the DNA sequence level and an example of convergent evolution. Warfarin inhibits blood clotting by binding to subunit 1 of the enzyme vitamin K epoxide reductase, VKORC1 (Li et al., 2004; Rost et al., 2004, 2005). This prevents VKORC1 from binding to vitamin $\mathrm{K}$, an essential step in blood clot formation.
Warfarin was first used as a pesticide to kill rats in the 1950s, and the first report of resistant populations appeared soon after (Boyle, 1960; see table 1 in Boyle for data that students could analyze as part of a classroom exercise or for homework). In the following decades, resistant populations of rats were identified around the world (see table 1 in Pelz et al., 2005 for data and references). Interestingly, resistant rats were not all genetically the same. There is substantial genetic variation for VKORC1 in rat populations (Pelz et al., 2005; Rost et al., 2009), and several different alleles confer varying degrees of resistance to warfarin. Variation at amino acid position 139 (Pelz et al., 2005; Rost et al., 2009) seems to have a particularly strong effect upon warfarin toxicity. This is not surprising; this amino acid is at the center of the putative binding site for warfarin. The wild-type codon for this amino acid is TAT, which codes for a tyrosine; rats with a tyrosine are susceptible to warfarin poisoning. Three mutations are present at this codon-TCT, TGT, and TTTwhich code for serine, cysteine, and phenylalanine, respectively. All of these mutations have relatively high levels of VKOR activity in the presence of warfarin.

Many biology majors are preparing for careers in medicine and are likely to find evolutionary examples related to humans more engaging than discussions of field mice or fruit flies. Fortunately, many compelling examples are available; three of which are described below.

\section{Antibiotic Resistance in Escherichia coli}

The emergence of antibiotic-resistant bacteria provides a dramatic example of how quickly evolution can occur. 
$\beta$-Lactam antibiotics are the most widely used group of antibiotics; examples include penicillin, amoxicillin, ampicillin, and cefotaxime - all of which have a $\beta$-lactam ring. Resistance to $\beta$-lactam antibiotics is mediated through hydrolysis of the $\beta$-lactam ring by the enzyme $\beta$-lactamase. Penicillin was first mass produced in 1943, and by 1947, the first penicillin resistant Staphylococcus aureus infections were found. By 1950, 40\% of $S$. aureus isolates were penicillin resistant.

There are several classes of $\beta$-lactamases, and substantial sequence variation within each class that affects the degree of antibiotic resistance. For example, the TEM-52 allele in E. coli reported in 1998 is $>4000$ times more resistant to cefotaxime than the wild-type E. coli allele TEM-1 (Poyart et al., 1998; Weinreich et al., 2006). The TEM-52 allele differs from the wild type by three amino acid substitutions (Table 2; see table 1 in Weinreich et al., 2006). Hall (2002) has shown in vitro that changing an additional nucleotide in TEM-52 would greatly increase its resistance (to 33,000 times greater than TEM-1 for cefotaxime) and predicts that such a bacterial strain will be someday be found in nature. One nice feature of this example is that the evolution of resistance requires changing multiple nucleotides. For this to occur, there must be a sequence of mutations for which each mutation increases antibiotic resistance. In vitro tests showed there were several such pathways that each increased the level of antibiotic resistance (Weinreich et al., 2006).

\section{Human Immunodeficiency Virus (HIV) Resistance in Humans}

A provocative question for students is whether humans are evolving, and a classroom discussion on this topic is guaranteed to elicit numerous misconceptions (e.g., humans are evolving to be balder). One way to help clear these misconceptions is to present a plausible case of selection in humans, and the HIV epidemic provides such a case. HIV kills approximately 2 million people per year (Joint United Nations Programme on HIV/AIDS, 2008). Most people are highly susceptible to HIV infection, but people that are homozygous for a relatively rare allele at the CCR5 locus are resistant. The CCR5 locus codes for the C-C chemokine receptor 5 protein, which is a transmembrane protein on the surface of white blood cells. HIV enters white blood cells by binding to CCR5, and many HIV drugs work by interfering with this

Table 2. $\beta$-Lactamase DNA sequences in E. coli that have varying levels of resistance to the antibiotic cefotaxime ${ }^{a}$

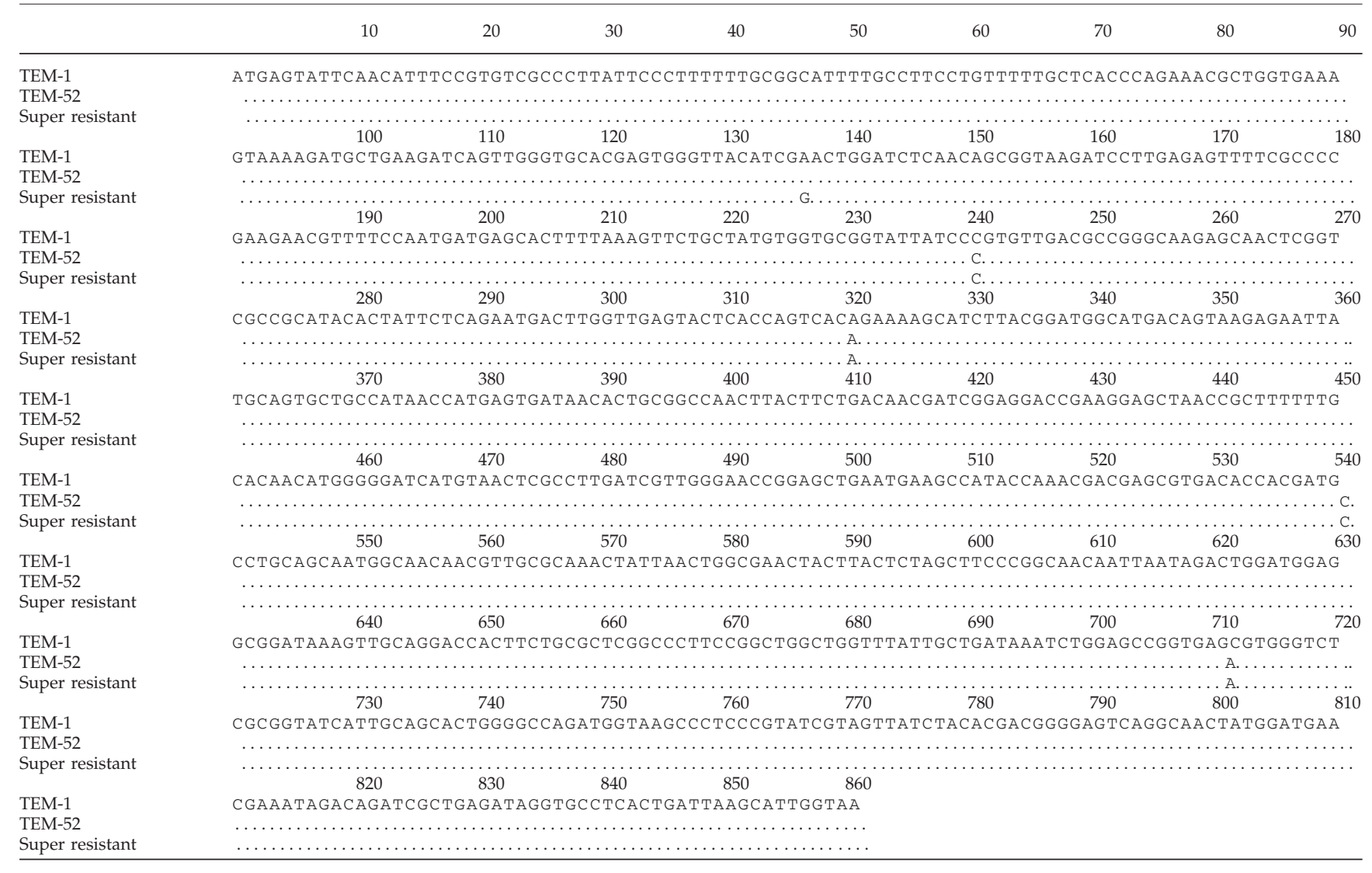

a TEM-1 is the wild-type sequence and has little resistance. TEM-52 is $>4000$ times more effective in breaking down cefotaxime. The "super resistant" strain has only been made in the lab, but is 33,000 times more resistant than TEM-1. The "super resistant" strain has mutations A42G, E104K, M182T, and G238S as described in table 1 of Weinreich et al. (2006). 
binding. CCR5- $\Delta 32$ is a CCR5 allele with a 32-base pair deletion (for review, see Hedrick and Verrelli, 2006). This deletion results in a nonfunctional receptor that inhibits entry of HIV into white blood cells. Individuals that are homozygous for CCR5- $\Delta 32$ have a high level of immunity to HIV (Dean et al., 1996; but incidentally, an increased risk to West Nile virus infection, Glass et al., 2006). CCR5- $\Delta 32$ has a frequency of approximately 0.10 in Europe but is virtually absent in Africa. To be protected from HIV infection, individuals need to be homozygous for CCR5- $\Delta 32$. With a frequency of 0.10 in Europe, we would expect the frequency of these homozygotes to be $(0.10)^{2}=0.01$, which is a nice example of the usefulness of the Hardy-Weinberg principle.

\section{Lactase Persistence in Humans}

The evolution of lactase production in humans provides another medically relevant example of natural selection. Lactose is a disaccharide sugar present in high concentration in milk that is broken down into the sugars glucose and galactose by the enzyme lactase-phlorizin hydrolase (lactase; note the opportunity to connect evolutionary biology with biochemistry). In most populations, children lose the ability to produce lactase after weaning. However, in populations that have had a long history of cattle domestications (e.g., Northern Europeans, East Africans), lactase production in adults is common (for review, see Wiley, 2008). Variation in lactase expression in adults is caused by a dominant allele upstream of the gene for lactase. Changing a cytosine to a thymine (C to T) 13,910 nucleotides upstream of the lactase gene confers lactase persistence (for a discussion of the genetic basis of lactase persistence, see Tishkoff et al., 2007, and references therein). The T-13910 allele has an especially high frequency among Northern Europeans, most of whom can digest milk as adults. However, this allele is nearly absent among pastoralists in East Africa who are lactase persistent. Tishkoff et al. (2007) recently showed that East Africans have an alternative allele (C-14010) that also confers lactase persistence. This is a nice example of convergent evolution. Analysis of DNA sequence variation among East Africans suggests that the C-14010 allele arose in the past $7000 \mathrm{yr}$, and conferred a reproductive advantage of approximately 7\% (Tishkoff et al., 2007).

\section{ELABORATED EXAMPLE OF TEACHING FOR CONCEPTUAL CHANGE WITH A DNA SEQUENCE}

\author{
"What professors do in their classes matters far less \\ than what they ask students to do."
}

Halpern and Hakel (2003)

Incorporating DNA sequences into natural selection instruction should increase student understanding of how populations evolve. However, as the quote by Halpern and Hakel (2003) implies, simply showing DNA sequences to students will not be as effective as using DNA sequences to get students to think about inheritance. Below, we describe how classroom instruction may use DNA sequences and teaching for conceptual change to introduce students to natural selection.
In the first chapter of On the Origin of Species, Darwin discussed how plants and animals have been bred to have desired characteristics, and used such "artificial" selection as an analogy to introduce how selection works in nature. The analogy is still powerful, and serves as an ideal introduction to natural selection (e.g., Dawkins, 2009). One of the most dramatic examples of the power of artificial selection is the creation of the diverse array of dog breeds from wolves (for a nontechnical review, see Lange, 2002), and a discussion of dog breeding provides an opportunity to introduce the genetic basis of selection. An instructor can begin such a discussion by telling the class that all dog breeds are descended from wolves, and asking the class "If you had a bunch of wolves, or perhaps a group of wolf-like dogs, and wanted a Chihuahua, how would you create one?" Students discuss the question in pairs.

The instructor then elicits responses from the entire class. A "correct" answer for this question is that Chihuahuas can be bred from wolves by selectively breeding small wolves with short faces and wiry tan hair for many generations. While soliciting responses, it is important that answers are obtained from a sufficient number of students that the full range of student answers is heard. This is important, because many students in the class will propose breeding Chihuahuas by raising wolves in a warm environment ("so they will not need such heavy fur") and providing them with plenty of food that is easy to eat ("so they become less aggressive and develop smaller teeth"). Such responses reveal the misconceptions that the environment causes individuals to evolve, and that traits evolve from their use or disuse.

Once a diversity of answers has been recorded on the board, and the class can see the need to reconcile the differences expressed, the instructor asks for comments on the feasibility of each proposal. This will create some cognitive conflict, and probably some confusion. Some students will clearly understand why raising wolves in domestic environments will not cause them to become Chihuahua-like. Others will not. The confusion can be resolved by making a connection to genetics. The instructor reminds the class that wolf pups grow up to be adult wolves because they have wolf genes not because they are raised in a forest. Wolves raised in a kennel or other domesticated environment will have the same genes and will still grow up to be wolves. Therefore, the breeding strategy of changing the wolf's environment will not work. In contrast, the selective breeding program will work because when a breeder preferentially chooses small, tan wolves to breed, he is selecting wolves with specific DNA sequences. The instructor shows the class DNA sequences for one of the genes that differentiate Chihuahuas from wolves. Body size in wolves and dogs is influenced by variation at the insulin-like growth factor 1 (IGF1) gene. Chihuahuas (and other miniature breeds) have an adenine at position $44,228,468$ in the dog genome and wolves have a guanine (Sutter et al., 2007).

A second example is then presented to reinforce the fact that selection-either artificial or natural-acts on genes. Leg length in dogs is affected by variation at the fibroblast growth factor 4 (FGF4) gene. Dogs with genotype $l l$ have short legs and dogs with genotype $L L$ have longer legs (Parker et al., 2009). Dachshunds, Pekingeses, and Basset Hounds all have genotype $l l$. After the instructor introduces 
Table 3. Partial cytochrome $c$ DNA sequences for eight species ${ }^{\mathrm{a}}$

Human

Chimpanzee

Mouse

Chicken

Frog

Trout

Fruit fly

Corn
CCACTACAACTCTTTCCGTTCTTCTAAAAATAATACTTCACAAGGGTCACGGTGTGGCAA

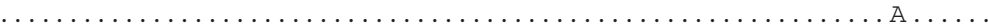
$\ldots \ldots \ldots$ T $\ldots \ldots \ldots \ldots \ldots \ldots \ldots \ldots$ C . GT $\ldots \ldots$ C $\ldots \ldots \ldots \ldots$. . C

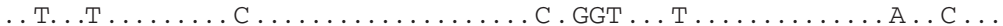

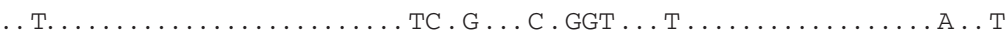
$\ldots \ldots$. . . .GA . C . T . . . CGT . . C.GGT . . . . . ... . . . . A . $\ldots \ldots \ldots \ldots \ldots \ldots$ C . T . . . . G . C . GC . CGT . GCG . GC ............ . CT. GGGTTGACGA . . C . . . . . G . G . TC . GG . . . GC . C . . . . . . G

${ }^{a}$ The human sequence starts immediately after the start codon. Note that the chimpanzee sequence is almost identical to the human sequence and that as the table is descended, species are more and more different from humans.

this example, a few follow-up questions are useful. The instructor asks the class how effective a Chihuahua breeding program would be if the IGF1 allele for small body size was not in the starting population, or what would happen to the IGF1 sequence of Dachshunds released into wild. Because learning difficult concepts such as natural selection requires seeing multiple examples of the concept at work, additional examples are discussed in subsequent lectures.

\section{SPECIATION, MACROEVOLUTION, AND THE HISTORY OF LIFE}

We have discussed how and why DNA sequences can be used to address student misconceptions relating to natural selection. We have emphasized natural selection in this essay because natural selection is one of the main components of evolutionary theory, and because student misconceptions regarding natural selection are widespread and persistent. However, we recognize that students also need to understand speciation, macroevolution, and the history of life (Cately, 2006). There has been less research on student misconceptions regarding these aspects of evolution (Baum et al., 2005; Gregory, 2008), but it is clear that many students do not understand how one species can evolve into another (e.g., a fish into a frog). One source of difficulty is that many students unconsciously believe that individuals in a species share an innate, immutable essence that is responsible for the common features of the species (Greene, 1990; Mayr, 2001; Medin and Atran, 2004; Shtulman, 2006). This worldview, called "essentialism," dismisses variation between individuals as unimportant, and makes natural selection, speciation, and macroevolution seem impossible. Historically, this type of thinking was manifested in the belief that speciation occurred via "saltations," mutations of large effect that instantly create new species (Mayr, 1982). Many authors (Mayr, 1982; Sinatra et al., 2008; Gregory, 2009) have emphasized the importance of replacing essentialism with "population thinking" (i.e., recognizing individual variation as important) for understanding evolution, and we agree that this is important. Incorporating DNA sequences into natural selection instruction should be useful for highlighting genetic variation between individuals.

We also believe that students also need to understand the genetic basis of the differences between species to understand macroevolution, and this second point has not been made in most discussions of the constraints of essentialism.
The precise genetic basis for phenotypic differences between species is seldom known, but there is no doubt that species are different because their genomes are different, which is to say they have different DNA sequences. This is a very important concept for students to understand. DNA is composed of a sequence of four nucleotides, and gene sequences for even distantly related species are often remarkably similar. Showing students DNA sequences from different species should demonstrate there is no reason why mutation and selection, operating gradually over a long time period, could not transform a species. Numerous examples are available. The classic example for eukaryotes is cytochrome $c$, which clearly shows that humans are genetically similar to other mammals (Table 3). The mitochondrial gene NADH is useful for illustrating relationships among primates, and the entire mitochondrial genome is useful for illustrating genetic relationships among people living in different parts of the world (Ingman et al., 2000) or the relationship between $\mathrm{Ne}$ anderthals and modern humans (Green et al., 2008).

For many genes, the rate of genetic change is approximately constant, so that the more closely related species are, the more similar their DNA sequences will be. This idea, the molecular clock, is covered in many introductory biology textbooks, and is one of the basic principles used to reconstruct evolutionary histories from genetic data. Classic examples of genetic differentiation between species show genes that have changed one nucleotide at a time, but mutation can take many forms, including insertion or deletion of sections of DNA, gene duplications, and entire chromosomal rearrangements. In addition, mutations affect not only the amino acid sequence of structural proteins and enzymes but also can affect gene expression and development. Discussing such mutations should take some of the mystery out of speciation and macroevolution.

\section{DISCUSSION}

Nehm and Reilly (2007) estimated that $86 \%$ of second-semester biology majors in a traditional introductory biology course finished the course with at least one evolutionary misconception. These results are probably typical (Brumby, 1984; Bishop and Anderson, 1990), and suggest that introductory biology courses are far less effective than instructors believe. If this is true, biology instructors may need to reassess how evolution is taught in introductory biology classes. Some instructors may conclude that natural selection is too 
difficult for introductory students to understand or is not worth the time required to teach effectively. We do not believe that such pessimism is justified. Natural selection may be difficult-almost impossible - to teach using traditional lectures. However, teaching methods specifically designed to address student misconceptions have not been assessed well enough to conclude that introductory biology students cannot learn natural selection. There is hope that carefully crafted learning exercises will help students recognize and replace evolutionary misconceptions, and we suggest that incorporating examples of DNA sequences into lectures on natural selection may be part of the solution.

The ultimate test of the approach we advocate is whether students replace misconceptions regarding inheritance with scientifically supported conceptions. The physics education literature shows that students can often successfully answer exam questions through rote memorization and pattern recognition (Hake, 1998), so assessment must be designed with care, and ideally, validated. The biology education community has just begun developing validated tests to measure student understanding of key biology principles (Klymkowsky and Garvin-Doxas, 2008; Smith et al., 2008), and one such test is available on natural selection. The Conceptual Inventory of Natural Selection (CINS; Anderson et al., 2002) is a 20-question, multiplechoice exam that uses common misconceptions as wrong answers. Nehm and Schonfeld (2008) have argued that the test would benefit from refinement, but until revised or new versions are available, the CINS is easy to use and provides valuable feedback regarding student misconceptions. When we used the CINS for the first time, we were surprised at some of the answers that students selected, and this experience was invaluable for redesigning our course.

Preliminary data from our introductory biology course at Montana State University suggests that the DNA examples that we describe in this essay are useful for promoting a clear understanding of natural selection. One of us (S.K.) teaches a sophomore-level introductory biology course that covers evolution. The class meets three times a week for 50 min, and once a week for a 3-h lab (Kalinowski et al., $2006 a, b)$. Lectures used several of the above-mentioned examples of DNA sequences to illustrate evolutionary concepts. The CINS was administered at the beginning and end of a 7-wk unit on evolution that included three lectures on natural selection. Ten of the 20 questions on the CINS (questions $4,6,7,8,9,13,15,17,19$, and 20) relate to genetic aspects of natural selection. The preinstructional class average for these 10 questions was $64 \%$. After instruction, the class average rose to $88 \%$. This increase in score represents a normalized gain (Hake, 1998) ${ }^{1}$ of $66 \%$. There is very little other CINS data to directly compare these results to, but a $66 \%$ normalized gain compares favorably to gains achieved on other exams for which students harbored common misconceptions (e.g., Hake, 1998), and shows that the class overcame many of their misconceptions. We interpret this result as suggesting that our teaching practices are effective,

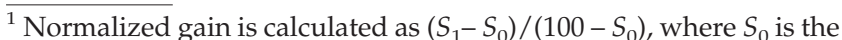
average score on an exam before instruction (on a 100-point scale) and $S_{1}$ is the average score on the same exam after instruction. It measures the proportion of the points that students missed on the initial exam that were not missed on the second exam.
}

but we acknowledge that a stronger study (i.e., one with a control) is required to draw firmer conclusions.

Natural selection and genetics are two of the most important ideas in biology but are difficult to understand when studied alone. Weaving DNA sequences into evolution education should improve student understanding. Because students need a strong conceptual framework of all biology to understand any biology, DNA sequences should be woven into instruction on biochemistry, physiology, and ecology-in short, all the topics covered in introductory biology courses. If this was done, students might have a better chance of understanding basic concepts such as natural selection.

\section{ACKNOWLEDGMENTS}

This essay was improved by S. K.'s recent participation in the National Academies "Summer Institute on Undergraduate Education" and by thoughtful comments from two anonymous reviewers. We thank BIOL 215 students at Montana State University for helping develop these ideas. This work was funded by the National Science Foundation grant DEB 0717456 and the Howard Hughes Medical Institute.

\section{REFERENCES}

Alters, B. J., and Nelson, C. E. (2002). Teaching evolution in higher education. Evolution 56, 1891-1901.

Anderson, D. L., Fisher, K. M., and Norman, G. J. (2002). Development and evaluation of the conceptual inventory of natural science. J. Res. Sci. Teach. 39, 952-978.

Bardapurkar, A. (2008). Do students see the "selection" in organic evolution? A critical review of the causal structure of student explanations. Evol. Educ. Outreach 1, 299-305.

Baum, D. A., Smith, S. D., and Donovan, S.S.S. (2005). The treethinking challenge. Science 310, 979-980.

Belk, M. C., and Smith M. H. (1996). Pelage coloration in oldfield mice (Peromyscus polionotus): antipredator adaptation? J. Mammal. $77,882-890$.

Bishop, B., and Anderson, C. (1990). Student conceptions of natural selection and its role in evolution. J. Res. Sci. Teach. 27, 415-427.

Boyle, C. M. (1960). Case of apparent resistance of Rattus norvegicus anticoagulant poisons. Nature 188, 517.

Bransford, J. D., Brown, A. L., and Cocking, R. R. (eds.). (2000). How People Learn: Brain, Mind, Experience, and School, Washington, DC: National Academies Press.

Bromham, L. (2009). Darwin would have loved DNA: celebrating Darwin 200. Biol. Lett. 5, 503-505.

Brumby, M. N. (1984). Misconceptions about the concept of natural selection by medical biology students. Sci. Educ. 68, 493-503.

Campbell, N. A., Reece, J. B., Urry, L. A., Cain, M. L., Wasserman, S. A., Minorsky, P. V., and Jackson, R. B. (2008). Biology, 8th ed., San. Francisco, CA: Pearson/Benjamin Cummings.

Cately, K. M. (2006). Darwin's missing link-a novel paradigm for evolution education. Sci. Educ. 90, 767-783.

Catrambone, R., and Holyoak, K. J. (1989). Overcoming contextual limitations on problem-solving transfer. J. Exp. Psychol. Learn. Mem. Cogn. 15, 1147-1156.

Cavener, D. R., and Clegg, M. T. (1975). Dynamics of correlated genetic systems. IV. Multilocus effects of ethanol stress environments. Genetics 90, 629-644. 
Coyne, J. (2009). Why Evolution Is True, New York: Viking.

Dawkins, R. (1986). The Blind Watchmaker, New York: W. W. Norton.

Dawkins, R. (2009). The Greatest Show on Earth: The Evidence for Evolution, New York: The Free Press.

Dean, M., et al. (1996). Genetic restriction of HIV-1 infection and progression to AIDS by a deletion allele of the CKR5 structural gene. Science 273, 1856-1862.

Demastes, S. S., Settlage, J., and Good, R. (1995). Students' conceptions of natural selection and its role in evolution: cases of replication and comparison. J. Res. Sci. Teach. 32, 535-550.

di Sessa, A. A. (2006). A history of conceptual change research: threads and fault lines. In: The Cambridge Handbook of the Learning Sciences, ed. K. Sawyer, Cambridge, MA: Cambridge University Press, 265-282.

Dobzhansky, T. (1937). Genetics and the Origin of Species, New York: Columbia University Press.

Dobzhansky, T. (1973). Nothing in biology makes sense except in the light of evolution. Am. Biol. Teach. 35, 125-129.

Freeman, S. (2008) Biological Science, 3rd ed., Upper Saddle River, NJ: Prentice Hall/Pearson Education.

Glass, W. G., McDermott, D. H., Lim, J. K., Lekhong, S., Yu, S. F., Frank, W. A., Pape, J., Cheshier, R. C., and Murphy, P. M. (2006). CCR5 deficiency increases risk of symptomatic West Nile virus infection. J. Exp. Med. 203, 35-40.

Green, R. E., et al. (2008). A complete neandertal mitochondrial genome sequence determined by high-throughput sequencing. Cell $134,416-426$

Greene, E. D. (1990). The logic of university students' misunderstanding of natural selection. J. Res. Sci. Teach. 27, 875-885.

Gregory, T. R. (2009). Understanding natural selection: essential concepts and common misconceptions. Evol. Educ. Outreach 2, 156-175.

Gregory, T. R. (2008). Understanding evolutionary trees. Evol. Educ. Outreach 1, 121-137.

Guzetti, B. J., Snyder, T. E., Glass, G. V., and Gamas, W. S. (1993). Promoting conceptual change in science: a comparative meta-analysis of instructional interventions from reading education and science education. Read. Res. Q. 28, 116-159.

Hake, R. R. (1998). Interactive-engagement versus traditional methods: a six-thousand-student survey of mechanics test data for introductory physics courses. Am. J. Phys. 66, 64-74.

Hall, B. G. (2002). Predicting evolution by in vitro evolution requires determining evolutionary pathways. Antimicrob. Agents Chemother. 46, 3035-3038.

Halpern, D. F., and Hakel, M. D. (2003) Applying the science of learning to the university and beyond. Change (July/Aug.): 37-41.

Hedrick, P. W., and Verrelli, B. C. (2006). 'Ground truth' for selection on CCR5-D32. Trends Genet. 22, 293-296.

Hewson, P. W., Beeth, M. E., and Thorley, N. R. (1998). Teaching for conceptual change. In: International Handbook of Science Education, ed. B. J. Fraser and K. G. Tobin, Dordrecht, The Netherlands: Kluwer Academic Publishers, 199-218.

Hoekstra, H. E., Hirschmann, R. J., Bundey, R. A., Insel, P. A., and Crossland, J. P. (2006). A single amino acid mutation contributes to adaptive beach mouse color pattern. Science 313, 101-104.

Huxley, J. (1943). Evolution, The Modern Synthesis, New York: Harper and Brothers.
Ingman, M., Kaessmann, H., Paabo, S., and Gyllensten, U. (2000). Mitochondrial genome variation and the origin of modern humans. Nature 408, 708-713.

Ingram, E. L., and Nelson, C. E. (2006). Relationship between achievement and students' acceptance of evolution or creation in an upper-level evolution course. J. Res. Sci. Teach. 43, 7-24.

Jensen, M. S., and Finley, F. N. (1996). Changes in students' understanding of evolution resulting from different curricular and instructional strategies. J. Res. Sci. Teach. 33, 879-900.

Joint United Nations Programme on HIV/AIDS (2008). Report on the Global HIV / AIDS Epidemic 2008. Geneva, Switzerland: UNAIDS. www. unaids.org/en/KnowledgeCentre/HIVData/GlobalReport/2008/ default.asp (accessed 14 April 2010).

Kalinowski, S. T., Taper, M. L., and Metz, A. M. (2006a). Can mutation and natural selection mimic design? A guided inquiry laboratory for undergraduate students. Genetics 174, 1073-1079.

Kalinowski, S. T., Taper, M. L., and Metz, A. M. (2006b). How are humans related to other primates? A guided inquiry laboratory for undergraduate students. Genetics 172, 1379-1383.

Kaufman, D. W. (1974). Adaptive coloration in Peromyscus polionotus: experimental selection by owls. J. Mammal. 55, 271-283.

Klymkowsky, M. W., and Garvin-Doxas, K. G. (2008). Recognizing student misconceptions through Ed's Tools and the Biology Concept Inventory. PLoS Biol. 6, e3.

Lamarck, J. (1809). Philosophie Zoologique, Paris, France (English translation: Elliot, H. Zoological Philosophy, Chicago, IL: The University of Chicago Press).

Lange, K. E. (2002). The evolution of dogs: wolf to woof. Natl. Geogr. Mag. (Jan. 2002): 2-11.

Li, T., Chang, C. Y., Jin, D. Y., Lin, P. J., Khvorova, A., and Stafford, D. W. (2004). Identification of the gene for vitamin $\mathrm{K}$ epoxide reductase. Nature 427, 541-544.

Mayr, E. (1982). The Growth of Biological Thought, Cambridge, MA: Harvard University Press.

Mayr, E. (2001). What Evolution Is, New York: Basic Books.

Mayr, E., and Provine, W. B. (1980). The Evolutionary Synthesis: Perspectives on the Unification of Biology, Cambridge, MA: Harvard University Press.

McDermott, L. (1998). Students' conceptions and problem solving in mechanics. In: Connecting Research in Physics Education with Teacher Eduction, ed. A. Tiberghien, E. Jossem, and J. Barojas, $\mathrm{OH}$ : ICPE Books, 1-11 www.physics.ohio-state.edu/ jossem/ICPE/ C1.html.

Medin, D. L., and Atran, S. (2004). The native mind: biological categorization and reasoning in development and across cultures. Psychol. Rev. 111, 960-983.

Mestre, J. (2003). Transfer of learning: issues and research agenda: report of a workshop held at the National Science Foundation. www.nsf.gov/pubs/2003/nsf03212/nsf03212.pdf.

Morgan, T. H. (1932). The Scientific Basis of Evolution, New York: W. W. Norton.

National Research Council (2005). How Students Learn: Science in the Classroom. Committee on How People Learn, A Targeted Report for Teachers, ed. M. S. Donovan and J. D. Bransford, Washington, DC: National Academies Press.

Nehm, R. H., and Reilly, L. (2007). Biology majors' knowledge and misconceptions of natural selection. Bioscience 57, 263-272.

Nehm, R. H., and Schonfeld, I. (2008). Measuring knowledge of natural selection: a comparison of the CINS, an open-response instrument, and an oral interview. J. Res. Sci. Teach. 45, 1131-1160. 
Nussbaum, J., and Novick, S. (1982). Alternative frameworks, conceptual conflict, and accommodation: toward a principled teaching strategy. Instr. Sci. 11, 183-200.

Parker, H. G., et al. (2009). An expressed Fgf4 retrogene is associated with breed-defining chondrodysplasia in domestic dogs. Science 325, 995-998.

Payne, F. (1910). Forty-nine generations in the dark. Biol. Bull 18, 188-190.

Pelz, H. J., et al. (2005). The genetic basis of resistance to anticoagulants in rodents. Genetics 170, 1839-1847.

Piaget, J. (1978). Success and Understanding, Cambridge, MA: Harvard University Press.

Posner, G. J., Strike, K. A., Hewson, P. W., and Gertzog, W. A. (1982). Accommodation of a scientific conception: towards a theory of conceptual change. Sci. Educ. 66, 211-227.

Poyart, C., Mugnier, P., Quesne, G., Berche, P., and Trieu-Cuot, P. (1998). A novel extended-spectrum TEM-type b-lactamase (TEM-52) associated with decreased susceptibility to moxalactam in Klebsiella pneumoniae. Antimicrob. Agents Chemother. 42, 108-113.

Rost, S., et al. (2004). Mutations in VKORC1 cause warfarin resistance and multiple coagulation factor deficiency type 2. Nature 427, 537-541.

Rost, S., Fregin, A., Hünerberg, M., Bevans, C. G., Muller, C. R., and Oldenburg, J. (2005). Site-directed mutagenesis of coumarin-type anticoagulant-sensitive VKORC 1, evidence that highly conserved amino acids define structural requirements for enzymatic activity and inhibition by warfarin. Thromb. Haemost. 94, 780-786.

Rost, S., Pelz, H. J., Menzel, S., MacNicoll, A. D., León, V., Song, K. J., Jäkel, T., Oldenburg, J., and Müller, C. R. (2009). Novel mutations in the VKORC1 gene of wild rats and mice-a response to 50 years of selection pressure by warfarin? BMC Genet. 10, 4 .

Sadava, D., Heller, H. C., Orians, G. H., Purves, W. K., and Hillis, D. M. (2008). Life: The Science of Biology, Sunderland, MA: Sinauer Associates.

Scott, P. H., Asoko, H. M., and Driver, R. H. (1991). Teaching for conceptual change: a review of strategies. In: Research in Physics Learning: Theoretical Issues and Empirical Studies, ed. R. Duit, F. Goldberg, and H. Niedderer, Kiel, Germany: IPN, 310-329.
Shtulman, A. (2006). Qualitative differences between naïve and scientific theories of evolution. Cogn. Psychol. 2, 170-194.

Sinatra, G. M., Brem, S. K., and Evans, E. M. (2008). Changing minds? Implications of conceptual change for teaching and learning about biological evolution. Evol. Educ. Outreach 1, 189-195.

Smith, M. K., Wood, W. B., and Knight, J. K. (2008). The genetics concept assessment: a new concept inventory for gauging student understanding of genetics. CBE-Life Sci. Educ. 7, 422-430.

Sumner, F. B. (1929). The analysis of a concrete case of intergradations between two subspecies. Proc. Natl. Acad. Sci. USA 15, $110-$ 120.

Sundberg, M. D., and Dini, M. L. (1993). Science majors vs nonmajors: is there a difference? J. Coll. Sci. Teach. 23, 299-304.

Sutter, N. B., et al. (2007). A single IGF1 allele is a major determinant of small size in dogs. Science 316, 112-115.

Tanner, K., and Allen, D. (2005). Approaches to biology teaching and learning: understanding the wrong answers-teaching toward conceptual change. Cell Biol. Educ. 4, 112-117.

Tishkoff, S. A., et al. (2007). Convergent adaptation of human lactase persistence in Africa and Europe. Nat. Genet. 39, 31-40.

Umina, P. A., et al. (2005). A rapid shift in the classic clinal pattern in Drosophila reflecting climate change. Science 308, 691-693.

Van Delden, W. (1984). The alcohol dehydrogenase polymorphism in Drosophila melanogaster: facts and problems. In: Population Biology and Evolution, ed. K. Wohrmann and V. Loeschcke, Berlin, Germany: Springer-Verlag, 127-142

Vosniadou, S. (2008). International Handbook of Research on Conceptual Change, New York: Routledge.

Vosniadou, S., and Brewer, W. F. (1987). Theories of knowledge restructuring in development. Rev. Res. Educ. 37, 51-67.

Weinreich, D. M., Delaney, N. F., DePristo, M. A., and Hartl, D. L. (2006). Darwinian evolution can follow only very few mutation paths to fitter proteins. Science 312, 111-114.

Weisman, A. (1889) Essays upon Heredity, Vol. 1 and 2. www. esp.org/books/weismann/essays/facsimile/ (accessed 8 March 2010).

Wiley, A. S. (2008). Cow's milk consumption and health: an evolutionary perspective. In: Evolutionary Medicine and Health, ed. W. R. Trevathan, E. O. Smith, and J. J. McKenna, New York, Oxford University Press, 116-133. 